\title{
INTERCAMBIO EDUCATIVO VIRTUAL: UNA CLASE VIRTUAL COMPARTIDA NORTE - SUD SOBRE DESARROLLO SOSTENIBLE
}

Augusta Abrahamse, Carla Quiroga, Mathew Johnson y Ruth Scipione

\section{RESUMEN}

Las competencias globales son, cada vez más, habilidades importantes que se deben adquirir desde pregrado. Un intercambio internacional representa un reto y es inviable para muchos estudiantes, por tanto, existe la necesidad de desarrollar e implementar medios alternativos para introducir experiencias internacionales e interculturales en las aulas de pregrado. En este trabajo se presenta un programa basado en intercambios virtuales, en el que se creó una materia virtual de un semestre, entre la Universidad Privada Boliviana en Bolivia y la Universidad de Siena en los Estados Unidos de Norte América, sobre desarrollo sostenible. La clase proveyó una experiencia multidisciplinaria e intercultural relevante tanto para los estudiantes de las carreras de ciencias puras e ingeniería como para los de ciencias sociales, sin la necesidad de viajar. Además, el proceso de aprendizaje, basado en la investigación y en la resolución de problemas, se fortaleció a través de la incorporación del servicio social que se realizó en colaboración con una organización rural boliviana, Unidad Académica Campesina Carmen Pampa. Los resultados de este emprendimiento muestran que los cursos virtuales compartidos pueden proveer experiencias internacionales a estudiantes de pregrado.

Palabras Clave: Educación Internacional, Aprendizaje Virtual, Colaboración Intercultural, Competencias Globales, Aprendizaje Activo. 